\title{
LA HIPERINFLACIÓN DE LOS DERECHOS FUNDAMENTALES: CONSIDERACIONES SOBRE SUS LÍMITES, POTENCIALIDADES Y SOBRE SU RELATIVA INDISPONIBILIDAD
}

\author{
THE HYPERINFLATION OF FUNDAMENTAL RIGHTS: \\ CONSIDERATIONS ABOUT THEIR LIMITS, POTENTIALITY AND RELATIVE \\ INVIOLABILITY
}

Juan Carlos Riofrío Martínez-Villalba

\begin{abstract}
Ph.D. por la Pontificia Università della Santa Croce y Doctor por la Universidad Católica Santiago de Guayaquil. Profesor de Derecho constitucional y de Teoría Fundamental del Derecho en la Universidad de Los Hemisferios (Quito, Ecuador), donde además ha sido Decano de la Facultad de Ciencias Jurídicas. Este trabajo se ha desarrollado dentro del proyecto de investigación "Derechos humanos y constitucionales" de la Universidad de Los Hemisferios. E-mail: juancarlosr@uhemisferios.edu.ec
\end{abstract}

Convidado

Doi: $10.5585 / \mathrm{rdb} . v 18 \mathrm{i} 7.764$

RESUMEN: Se consideran aquí los aspectos potenciales de los derechos humanos y constitucionales, para luego deducir las respectivas consecuencias. El capítulo I muestra la incongruencia de que todo derecho (incluido el derecho al sombrero, a una merienda proporcionada y al trato cálido) sea indisponible. El capítulo II define los elementos esenciales que todo derecho subjetivo debe tener para serlo. El capítulo III distingue los derechos subjetivos realizados (actuales), de los hipotéticos (potenciales): solo hay derecho realizado si en la realidad cotidiana alguien puede exigir algo a otro; antes solo será una posibilidad, una hipótesis de trabajo más o menos justificada en un texto doctrinal, constitucional o de derechos humanos. El capítulo IV muestra los aspectos potenciales que presentan los derechos, siguiendo la doctrina de la pirámide invertida $\mathrm{y}$, al hilo de la misma doctrina, el capítulo $\mathrm{V}$ delimita los aspectos indisponibles de los derechos. Finalmente se concluye que los aspectos potenciales y los aspectos indisponibles están delimitados por la realidad extramental, por la razón humana y por los actos de voluntad (normas, negocios, actos jurídicos, etc.). Como cada uno de estos tres factores actúa de modo distinto, la indisponibilidad de los derechos resulta ser un concepto flexible y progresivo.

Palabras clave: Derechos fundamentales. Imprescriptibilidad. Inalienabilidad. Inembargabilidad. Inviolabilidad.

ABSTRACT: We consider here the potential aspects of human and constitutional rights. Then we deduce the respective consequences. Chapter I shows the incongruity that any right (including the right to a hat, to a proportionate snack, and to a warm treatment) could be indefeasible. Chapter II defines the essential elements that every subjective right must have. Chapter III distinguishes between "real subjective rights" and "hypothetical rights": there is only a "real subjective right" if in reality one can demand something from another; previously it will be only a hypothesis of work, more or less justified, in a doctrinal or constitutional text, or in a treaty of rights. Chapter IV shows the potential aspects of rights, following the doctrine of the inverted 
pyramid of Riofrío. Chapter V, following this same doctrine, shows what the indefeasible aspects of rights are. Finally, it is evident that the potential and indefeasible aspects are delimited by the extramental reality, by human reason and by acts of will (norms, business, legal acts, etc.). As each of these three factors acts differently, the indefeasibility of rights becomes a flexible and progressive concept.

Keywords: Fundamental Rights. Imprescriptibly. Inalienability. Indefeasibility. Inviolability.

SUMARIO: 1. La concepción de los derechos fundamentales en la historia; 2. Elementos de la esencia del derecho subjetivo; 3. Derechos subjetivos realizados y derechos subjetivos hipotéticos; 4. La potencialidad de los derechos fundamentales; 5. Los límites de la potencialidad: lo indisponible; Conclusiones; Referencias.

\section{INTRODUCCIÓN HISTÓRICA}

A inicios del movimiento constitucional la doctrina era prácticamente unánime en fundamentar los principales derechos en la naturaleza y en la dignidad humana. Así aparece en documentos de época como la Declaración de los Derechos del hombre y del ciudadano de $1789^{1}$, la Declaración de Virginia de $1776^{2}$, entre otros. Uno de los textos más preclaros lo encontramos en la segunda oración del Acta de Independencia de los Estados Unidos de América que dice: "Sostenemos como evidentes estas verdades: que los hombres son creados iguales; que son dotados por su Creador de ciertos derechos inalienables; que entre éstos están la vida, la libertad y la búsqueda de la felicidad"3. Como tal naturaleza y dignidad eran inderogables, se entendía que estos derechos heredaran las características de ser indisponibles, imprescriptibles, inalienables, inembargables, inviolables, etc. Esos sí eran, en aquellos años, derechos "fundamentales": fundamentales para sobrevivir, fundamentales para ser tratados dignamente, como seres humanos.

Consolidado el constitucionalismo, los tiempos cambiaron y el Constituyente cada vez sintió tener más potestad de sancionar como derecho cualquier cosa que le parecía bien. No en vano se ha dicho que las constituciones son "corsarios" $"$ que arremeten donde quieren, incluso en trivialidades como la regulación del uso del sombrero (fez o tarbush) ${ }^{5}$, la obligación de tratar con "calidad y calidez" al consumidor ${ }^{6}$ o de dar una merienda proporcionada ${ }^{7}$. Todo puede llegar a ser "derecho constitucional" si el constituyente lo mete en el código. Por esto en los años siguientes fue atenuándose la preocupación por justificar la "fundamentalidad" del derecho y su relación con la dignidad humana. Durante el positivismo campante de fines del siglo XIX y de

\footnotetext{
${ }^{1}$ Su art. I dice: "Los hombres nacen y permanecen libres e iguales en derechos".

${ }^{2} \mathrm{Su}$ art. I dice: "que todos los hombres son por naturaleza igualmente libres e independientes, y tienen ciertos derechos inherentes".

${ }^{3}$ Como bien es sabido, la concepción americana de los derechos es prendataria de las tesis de natural right de John Locke y se anclan más directamente en la naturaleza humana. La noción es en parte distinta en el viejo continente. Los avatares europeos hicieron comprender los derechos más como "libertades públicas", como conquistas de los gobernados ante el Ancient Regime. En cualquier caso, la lucha por conseguirlos tenía una justificación relacionada con la dignidad de las personas y con lo que a cada uno corresponde por naturaleza.

${ }^{4}$ La expresión es de Sagües, quien señala que "en sentido figurado, puede sostenerse que el derecho constitucional es una suerte de corsario del mundo jurídico, en el sentido de que el constituyente puede capturar a su arbitrio temas de otras disciplinas (como asuntos de derecho laboral, civil, procesal, etc.), y llevarlos a la constitución, cuando los repute asuntos fundamentales o principales de la organización estatal, con lo que esos asuntos quedan "constitucionalizados". Ello es formalmente cierto, pero el ejercicio desmesurado e irresponsable de tal facultad engrosa a la constitución y provoca una crisis de identidad para ella, que termina confundiéndose con el derecho infraconstitucional" (SAGÜES, 2004, p. 60).

${ }^{5}$ Constitución de Turquía, 1961, art. $153 \S 2$.

${ }^{6}$ Tal derecho consta en la Constitución de Ecuador, 2008, arts. 27 y 362.

${ }^{7}$ Constitución del Neuquén (Argentina), art. 257, lit. d).
}

Revista de Direito Brasileira | São Paulo, SP | v. 18 | n. 7 | p. 49 - 62 | Set./Dez. 2017 
inicios del siglo $\mathrm{XX}$, tanto en la versión de la sociología jurídica como del positivismo kelseniano, los derechos se desgajaron de su anclaje natural: derecho pasó a ser, en la práctica, aquello que la autoridad lograba imponer como derecho. Curiosamente, estos nuevos derechos meramente positivos - que resultaron ser derecho porque el Constituyente los escribió en un papel— también heredaron las características de ser indisponibles, imprescriptibles, inalienables, etc.

El positivismo se popularizó hasta más o menos la mitad del siglo $\mathrm{XX}$, pero tras la gran guerra los doctrinarios se procuraron apartar paulatinamente de aquella visión. ¿Cómo explicar que las leyes nazis no eran derecho? Mil respuestas se dieron. La que triunfó en Núremberg fue la fórmula Radbruch ${ }^{8}$ : la injusticia extrema nunca será derecho, una ley intolerablemente injusta jamás es derecho, un acto manifiestamente injusto no puede ser derecho.

En tal encrucijada nace la Declaración Universal de los Derechos Humanos, concebida como una síntesis de aquellos derechos nucleares que la Sociedad de Naciones se obligaba a respetar. Quienes la redactaron no llegaron a ponerse de acuerdo en por qué debían reconocerse esos derechos ${ }^{9}$, sino simplemente en que debían reconocerse. A esta declaración le siguió una larga lista de pactos internacionales con fines similares. Sin embargo, el mundo comenzó a experimentar un estado de paz, bienestar y lujo como jamás se había visto. ¿Qué hacer si ya se había conseguido lo "fundamental" para sobrevivir, aquello más directamente atado con la dignidad humana? Simple: luchar por el saldo, por aquello que no era tan "fundamental". Entonces los Estados se sintieron en el deber de consagrar como derecho constitucional toda necesidad humana, toda aspiración, todo sueño, y, luego, incluso todo lo que cause de algún modo bienestar a la persona, a los animales o al medio ambiente. No extraña que la voz "fundamental" cada vez se use menos y que incluso haya desaparecido de algunas constituciones ${ }^{10}$.

Lo paradójico es que, sin mayor justificación que la de estar en un mismo saco, todas estas aspiraciones también heredaron las notas de indisponibilidad, inderogabilidad, imprescriptibilidad, inembargabilidad, inviolabilidad, etc. propias de los derechos verdaderamente "fundamentales". Hoy la confusión es tan grande que ya no se detecta la importancia singular de cada derecho. Hasta se ha llegado a afirmar que "todos los principios y los derechos son [...] de igual jerarquía" (art. 11.6 de la Constitución del Ecuador de 2008), como si el derecho al sombrero o a la hamaca valieran lo mismo que el derecho a la vida.

Ante tal hiperinflación de derechos indisponibles no es raro que surgieran voces como la de Michel Villey o la de Richard Rorty que descalificaran tales derechos por no ser verdaderos derechos, sino creaciones superfluas, fruto del capricho o de las emociones ${ }^{11}$. Villey y McInerny insistirán en que los derechos humanos son un invento moderno (el invento de los "derechos subjetivos"), sin contrapartida en la concepción jurídica antigua o medieval ${ }^{12}$.

\footnotetext{
${ }^{8}$ RADBRUCH, 1946. Según la teoría de Radbruch, el juez no debe aplicar la ley que sea incompatible con los principios de justicia sustancial a un nivel intolerable, ni la ley que contradiga explícita y abiertamente el principio de igualdad, que para el autor es el fundamento de toda justicia.

${ }^{9}$ En todo caso, vale señalar que jugó un papel de primera línea el iusnaturalista Jacques Maritain, quien encuestó a muchos hombres notables, algunos filósofos como Benedetto Croce o historiadores como E. H. Carr, literatos como Aldous Huxley, o políticos humanistas como el Mahatma Gandhi. Cfr. VILLEGAS, 1992, p. 131. Maritain siempre entendió la declaración de 1948 como un paso más en la institucionalización de los tradicionales derechos naturales. Cfr. BEUCHOT, 1993, p. 9-26.

${ }^{10}$ En concreto, la Constitución de Ecuador ha evitado de propósito utilizar la expresión "derechos fundamentales".

${ }^{11}$ Para Villey los derechos humanos son irreales, ilusorios y peligrosos porque prometen cosas que no se pueden conseguir, porque por ello acarrean desilusión y porque dejarán a muchos resentidos. Cfr. VILLEY, 1972, p. 12.

Rorty (1994) los considera como fruto de las emociones, porque estos derechos solo fueron pactados después del sufrimiento padecido en las dos guerras mundiales.

${ }^{12}$ Cfr. McINERNY, 1991, p. 1-2 y 13-14.

Revista de Direito Brasileira | São Paulo, SP | v. 18 | n. 7 | p. 49 - 62 |Set./Dez. 2017
} 


\section{ELEMENTOS DE LA ESENCIA DEL DERECHO SUBJETIVO}

Aunque no seguimos en todo a Villey, ni a McInerny, compartimos que aquí el problema de fondo son los "derechos subjetivos". ¿Son ellos meras aspiraciones? ¿o acaso concesiones generosas de la autoridad? ¿Qué verdaderamente son?

La primera noción de derecho (ius), acogida durante casi dos milenios, fue la de ser to dikaione, lo igual, la res iusta, lo justo: una cierta relación real de igualdad relativa entre lo que se recibe y lo que se debe a otro en razón de justicia ${ }^{13}$. La identificación de ius con el derecho subjetivo no se produjo sino tardíamente ${ }^{14}$. Ya se detecta este giro allá por el siglo XIII ${ }^{15}$, pero fue a partir del siglo XV cuando se generalizó ese giro donde el derecho ya no era la cosa justa, sino la facultad de exigir lo justo. Contribuirá a dar este paso Francisco Suárez († 1617), jesuita que ejercerá un enorme influjo en el extenso orbe. El fraile granadino dejará de concebir el derecho como lo igual, para entenderlo en un sentido más subjetivo, algo así como una facultad del sujeto de derecho acerca de lo suyo ${ }^{16}$. Los juristas de la segunda escolástica tratarán de resaltar la vinculación del derecho subjetivo con lo justo, con más o menos éxito. A otros autores posteriores les preocupará menos esta relación con lo justo, y finalmente la concepción voluntarista se extremará: derecho subjetivo será un simple poder, una potestad cualquiera, una facultad de exigir algo, lo que sea, sin más justificación que la coacción o el deseo del legislador.

Mucha agua ha corrido desde el lejano siglo XV, pero la noción de derecho subjetivo antes mencionada se ha mantenido incólume en lo fundamental. Recientemente se lo ha entendido como aquella "situación jurídica subjetiva consistente en la facultad o conjunto de facultades de exigir, de poseer o de ejercitar un derecho"17.

Creemos que los derechos subjetivos presentan tres aspectos metafísicos: un pasado actual, un futuro potencial, y un objeto sobre el que recae ese pasado y ese futuro.

a) Un pasado actual (actual entendido como "acto"), porque nadie ostenta un derecho de manera injustificada; algo o alguien (un acto jurídico, un contrato, el legislador, etc.) debe haberle adjudicado ese derecho. No hay derecho subjetivo sin alguna suerte de adjudicación, justificación, título o atribución de la cosa. Una compraventa es un acto jurídico voluntario que representa el título de la adquisición de un terreno. El derecho a la vida se justifica desde que se posee un "acto de ser" con naturaleza humana; la inteligencia actúa y concluye que el ser humano es tan valioso que hay que respetarlo, "atribuyendo" así el derecho al respeto a la vida ${ }^{18}$. No toda necesidad (como la de pagar la renta), ni toda aspiración (como la de tener un cónyuge virtuoso) es inmediatamente un derecho, sino sólo aquella justificada en algún criterio jurídico. Esto es algo que con frecuencia olvidan quienes redactan los catálogos de derechos.

\footnotetext{
${ }^{13}$ Así lo entendieron Aristóteles, Tomás de Aquino y varios juristas clásicos. Ius es lo igual, lo justo, no más, no menos. Quien adquiere un vehículo debe pagar lo justo, lo acordado, el precio del carro, no más, no menos; quien por desgracia atropella a otro debe pagarle el hospital, el costo de los daños, lo que dejó de ganar mientras estuvo accidentado... no más, no menos. La res iusta es un parámetro absolutamente racional. Cfr. RIOFRÍO, 2016, capítulo III.

${ }^{14}$ Cfr. GALLEGO GARCÍA, 2005.

15 Guillermo de Ockham entendió el derecho como "toda potestad lícita" (Opus nonaginta dierum; HERVADA, 2000, pp. 251-252).

16 Suárez sostiene que en sentido estricto "suele llamarse con propiedad ius o derecho, a cierta facultad moral, que cada uno tiene, acerca de lo suyo o de lo debido a sí; y así, el dueño de una cosa se dice que tiene derecho en la cosa, y el operario se dice que tiene derecho al salario, por razón del cual derecho se dice que es digno de su paga" (De legibus: lib. I, cap. II, n. 4). Obsérvese el esfuerzo de los juristas de la segunda escolástica en resaltar la vinculación con lo debido, con la cosa justa.

${ }^{17}$ MIRAS, CANOSA y BAURA, 2001, p. 344.

${ }^{18}$ En esta línea Hervada señala que los derechos pueden tener un título positivo, como la ley o un contrato, o un título natural, como la naturaleza humana. Cfr. HERVADA, 1981, p. 26-27, 48-50, 104, 107, 138 nota 41. No hay derecho sin título. Así, "para averiguar si existe derecho basta buscar el título" (p. 49).
}

Revista de Direito Brasileira | São Paulo, SP | v. 18 | n. 7 | p. 49 - 62 | Set./Dez. 2017 
b) A la vez, el derecho subjetivo implica un futuro potencial: un poder o facultad de disponer de mil maneras, o incluso de no disponer de aquello que se ha adjudicado o atribuido. Quien compra un terreno, puede venderlo, alquilarlo, darlo en fideicomiso, titularizarlo, etc. La vida se puede respetar no solo no matando, sino instaurando un seguro público, obligaciones privadas de cuidado, regulando las prácticas hospitalarias, etc. Para el titular, el derecho subjetivo implica un poder facultativo de disponer algo adjudicado, una capacidad jurídica sobre una cosa atribuida para decidir su destino.

c) La atribución pasada y la facultad futura de disposición versan siempre sobre un objeto de derecho. El derecho subjetivo sólo existe cuando hay una relación entre un sujeto de derecho (el titular) y una cosa a la que está facultado. Lo normal es que el derecho subjetivo se vea de forma abstracta: no se mira a un individuo específico a quien exigir algo, sino a un sinnúmero de sujetos hipotéticos que eventualmente podrían aparecer; la exigencia se concretará a su tiempo cuando se trabe una relación jurídica donde el titular del derecho subjetivo pueda decidir ejercitar su facultad. Robinson Crusoe no podía exigir nada a nadie, ni siquiera el respeto a su vida, hasta que Viernes llegó a su isla.

La mencionada facultad está más directamente relacionada con una acción. En general las acciones pueden encuadrarse en una de las categorías tradicionales: hacer, poseer, ejercitar u omitir cualquiera de estas cosas. Tales acciones tienen como contrapartida las clásicas obligaciones del deudor: dar o no dar, hacer o no hacer. Pero como las acciones suelen recaer sobre cosas, por extensión cabe decir: "tengo derecho (subjetivo) a mi casa", "págame mi derecho", etc. De esta manera el derecho subjetivo extiende su cobertura sobre las cosas.

Finalmente conviene aclarar que el derecho subjetivo estrictamente versa sobre "lo propio". Por eso, no suele considerarse que son derechos subjetivos las potestades (que son la capacidad de incidir sobre terceros), las competencias (que son las funciones de un sujeto abstracto o de un cargo), las expectativas de derecho y los intereses concretos o difusos (que por no ser derechos consolidados, su objeto no llega a ser algo absolutamente "propio"). Tampoco son derecho subjetivo, stricto sensu, las obligaciones. Todo esto, sin perjuicio de que indirectamente haya un cierto derecho reflejo a cumplir una obligación, a ejercer cierta potestad o competencia, a defender cierta expectativa, etc.

Si no se cumplen estos tres presupuestos metafísicos simplemente no habría derecho subjetivo. Las largas listas de derechos serían entonces, como diría Villey, derechos irreales, ilusorios y peligrosos ${ }^{19}$.

\section{DERECHOS REALIZADOS Y DERECHOS HIPOTÉTICOS}

La idea principal sobre la que se centra el análisis es la siguiente: en la realidad práctica no existe ningún derecho subjetivo, sino dentro de una relación jurídica trabada. Mientras esta relación no exista, los derechos subjetivos serán meros entes ideales, puras hipótesis de trabajo (pese a que tengan - y deban tener - alguna base en la realidad extramental). Nos explicamos.

Donde no hay relación, no hay derecho. Clásico ejemplo de un no-relacionado es Robinson Crusoe: mientras no desembarcó Viernes en su isla, éste ser solitario no era sujeto de derecho, pues no podía exigir nada a nadie. Los sujetos son lo más indiscutido de la relación jurídica y del derecho. Ubi ius ibi societas, dice una máxima medieval de origen desconocido. Talamanca señala que no deja de ser verdad la fórmula inversa: ubi societas ibi ius (TALAMANCA, 1990, p. 15). La verdad es que no es necesaria una sociedad muy populosa para que exista el derecho. Bastan dos personas: un acreedor y un deudor, alguien a quien otro deba algo en justicia. Tampoco tienen que ver con el derecho - por no estar relacionadas - las cosas

${ }^{19} \mathrm{Cfr}$. lo dicho a nota 11.

Revista de Direito Brasileira | São Paulo, SP | v. 18 | n. 7 | p. 49 - 62 |Set./Dez. 2017 
absolutamente desconocidas, como las fuentes de energía aún no descubiertas, y aquellas sobre las que el ser humano carece de dominio, como las lejanas galaxias.

Para que exista un derecho subjetivo real deben verificarse todos y cada uno de los elementos de la relación jurídica. Recordamos que ella era aquella relación de complementariedad que se da entre dos sujetos sobre una cosa, donde uno debe a otro esa cosa en justicia ${ }^{20}$. De la definición extraemos los siguientes elementos: (i) los elementos materiales, que son los sujetos, la cosa y el entorno circunstancial; y, (ii) los elementos formales, que son las relaciones que se dan entre los tres elementos materiales (las relaciones persona-cosa de titularidad positiva y negativa, de lo suyo, de lo ajeno; la relación interpersonal que mantienen los sujetos de derecho; y, las relaciones entorno-cosas y entorno-sujetos) $)^{21}$. No basta que existan dos sujetos, una cosa y un entorno, sino que todos estos elementos deben estar relacionados. Solo entonces alguien podrá exigirle a otro su derecho.

¿Entonces qué resultan ser los catálogos de derechos humanos, los derechos mencionados en las constituciones, e incluso los derechos naturales "en estado de naturaleza"? Mientras no se trabe una relación jurídica, nadie puede exigir nada a nadie. Hasta que esto suceda los catálogos de derechos serán puros juicios hipotéticos del legislador, y los derechos naturales puros razonamientos que indican de manera general cómo actuar con justicia cuando se configuren determinados supuestos. Robinson Crusoe era un marinero inglés de York, titular por tanto de todos derechos y libertades de los ingleses, que no pudo ejercer durante 28 años, hasta que desembarco otro ser humano a su isla. Cuando apareció Viernes, podía exigirle ciertas cosas previstas en las leyes inglesas, como el respeto a la libertad de expresión consagrada en 1695, pero en cambio le resultaba imposible ejercer otros derechos como el de participar en las elecciones parlamentarias previsto en el Bill of rights de 1689, al menos mientras permaneció en la isla. Aunque la hipótesis legal decía que ostentaba el derecho a votar, las circunstancias se lo impedían.

En todo caso, vale señalar que las mencionadas hipótesis no son meras ficciones: al contrario, deben partir de la realidad y han de ser razonables. Una declaración del derecho a la vida presupone que existe la vida y que su valor es tan alto, que es razonable respetarla. Una constitución que reconozca el derecho al pleno empleo será en buena medida demagógica, por no percatarse de que siempre existirá una tasa de desempleo. Igual de inaplicable era la ley nazi que obligaba a torturar o a matar, desconociendo los derechos básicos de los judíos, por ser sumamente irrazonable.

En conclusión, para que nazca un derecho subjetivo hipotético (o potencial) basta que se verifiquen los tres elementos de la esencia del derecho subjetivo: un título, una cosa (hipotética o real) y una facultad sobre esa cosa, la misma que se puede ejercer en la hipótesis de que se cumplan determinadas circunstancias. Pero para que de verdad alguien pueda exigir un derecho a otro, para que de verdad exista un derecho subjetivo realizado (o actual), ha de trabarse una relación jurídica que cumpla con aquellas circunstancias hipotéticas.

\footnotetext{
${ }^{20}$ Los autores son unánimes en aceptar que en la relación jurídica existe un vínculo y una pluralidad de sujetos. Muchos autores añaden otros elementos: "una regla jurídica" (Savigny), un derecho subjetivo (Balbín), la coactividad (Legaz Lacambra), etc. y generalmente se olvida que debe haber una cosa objeto de la relación (cosa que algunos reducen a un "hecho", en contraposición con el deber ser de la norma). Aquí procuraremos estudiar la relación jurídica desde una perspectiva más metafísica. Bajo esta visión Balbín ha señalado que "el fundamento de la relación jurídica positiva, lo que la constituye en el sujeto, es el derecho-facultad o potestad jurídica. Así la norma otorga a una persona la potestad jurídica o derecho-facultad, que es una cualidad; y ésta origina una relación al objeto jurídico o término de la relación. El sujeto jurídico, en virtud de un concreto derecho, se refiere al objeto. Esa referencia es la relación jurídica. Puede observarse lo que es tan característico de la relación: esa débil y sutil entidad, un mero respectus — real- por el que la substancia se refiere a otra cosa. Su esse, su realidad, es el de la substancia; su peculiar talidad, el respectus" (BALBÍN, 1985, p. 190-191).

${ }^{21}$ Además están los elementos metafísicos generales a toda realidad cósmica, como el acto, la potencia, el cambio y el tiempo. Sobre ellos hemos ahondado en Metafísica jurídica realista, 2016, pp. 78-93, 298.
}

Revista de Direito Brasileira | São Paulo, SP | v. 18 | n. 7 | p. 49 - 62 | Set./Dez. 2017 


\section{LA POTENCIALIDAD DE LOS DERECHOS FUNDAMENTALES}

El derecho subjetivo permanecerá como una mera posibilidad mientras no se configuren las circunstancias que permitan a su titular exigirlo a otro sujeto. Por ejemplo, según los pactos de derechos humanos todos tenemos derecho a disponer de nuestras propiedades, pero mientras no tengamos ninguna, de nada podemos disponer. Sólo cuando se trabe la relación jurídica apropiada habrá nacido realmente un derecho que podrá ejercerse, disponiendo o no de la cosa, haciéndolo de una u otra manera. Quien efectivamente haya prestado podrá exigir su pago dentro del plazo previsto, podrá conceder una prórroga, condonar la deuda, bajar la tasa de interés... estará así en potencia de realizar muchas acciones.

Con lo cual, hay que distinguir dos tipos de potencialidades o posibilidades: las del derecho subjetivo hipotético y las del derecho subjetivo realizado. En general, los autores se refieren a la potencialidad del derecho subjetivo actual, a aquellas posibilidades reales nacidas después de trabada la relación jurídica. Leibniz, por ejemplo, señalaba que "el derecho es la potencia del hombre bueno" 22 , la facultad de hacer o no $\operatorname{algo}^{23}$.

Menos se repara en las posibilidades que se abren antes de trabarse la relación jurídica. Aquí podemos distinguir tres escalones de potencialidad: el de la realidad, el de la inteligencia y el de la voluntad ${ }^{24}$. (i) La realidad ofrece muchas posibilidades jurídicas, faculta al individuo a realizar un sinnúmero de acciones; pero, a la vez, posee sus propios límites. Un teléfono no sirve para coser, ni una cosedora para llamar, por lo que no puedo firmar un contrato de telefonía vendiendo una cosedora, ni viceversa. (ii) La inteligencia humana capta la realidad, pero solo parcialmente, porque para tener un conocimiento absoluto de las cosas haría falta ser Dios. El hombre siempre podrá seguir descubriendo cosas en la naturaleza y esto delimita el derecho. El petróleo siempre fue el que fue, pero hace dos mil años sólo permitía firmar contratos relacionados con las antorchas; a partir del descubrimiento del motor se multiplicaron sus usos, su valor, y las clases de contratos que podían hacerse sobre él (v. gr. contratos de concesión, de transporte, de refinamiento, etc.). Mientras más se conoce la realidad, más posibilidades tiene el ser humano de usarla. (iii) Finalmente, la voluntad concreta aún más esas posibilidades cuando opta por alguna de las posibilidades que le ofrece la inteligencia (no se puede escoger lo que se desconoce). Quien tiene un teléfono lo puede alquilar, vender, usar, etc. Toda ley es una decisión voluntaria que concreta las posibilidades jurídicas en un país: un Constituyente puede decantarse por la monarquía o por la democracia, pero una vez escogido un sistema, el otro queda excluido; luego la ley especificará el modo de participación democrática, a través de elecciones directas o indirectas, de un gobierno republicano o parlamentario, etc. y la regulación inferior concretará aún más las infinitas posibilidades que hay de democracia, fijando circunscripciones, determinando el día de la elección y el lugar donde se debe votar, etc. Con cada nuevo acto normativo se reducen las posibilidades jurídicas de los sujetos. Así, para un ciudadano de a pie el alto y magno derecho fundamental a la democracia en la práctica solo llega a ser el derecho a presentarse el día $\mathrm{X}$, en la mesa $\mathrm{Y}$, para recibir una papeleta donde deberá poner un visto sobre el candidato de su elección.

Conviene destacar que cada escalón de esta pirámide invertida reduce la potencialidad jurídica a su modo. El piso de la realidad lo hace de manera forzosa: el ser humano no puede decidir a qué velocidad caerán los objetos en la tierra, ni cuánto será el resultado de una suma. El escalón intelectual delimita las posibilidades jurídicas según la claridad propia de la inteligencia:

\footnotetext{
${ }^{22}$ LEIBNIZ, 1991, p. 83.

${ }^{23}$ Leibniz señalaba que el derecho es “el poder moral de hacer o no hacer padecer” (en GUILLÉN, 1991, p. XXXV). El derecho no es del hombre malo, porque él carece de ciertos derechos, como cuando se le impone una sanción.

${ }^{24}$ Partimos de nuestra consideración de las fuentes del derecho y de la noción de la pirámide invertida expuesta en otros trabajos. Cfr. RIOFRÍO, 2016, capítulos IV y V; 2014; 2012, p. 259-308.
} 
si se conoce bien el petróleo, se conocerán bien sus posibilidades jurídicas, si se conoce de manera confusa la sexualidad humana, no se entenderá el matrimonio. Finalmente, en el peldaño de la voluntad (donde están las normas, actos, contratos y demás negocios jurídicos) los límites vienen impuestos por lo decidido, de la manera decidida. Para decidir hace falta competencia, conocimiento y voluntad, sin lo cual simplemente no hay decisión o ella nace viciada. Por otro lado, la decisión se puede manifestar en un gesto, en una palabra, en un signo o en un escrito. En un gesto como el de la mano del César que indulta al gladiador, en una palabra como el placet del rey, en un signo como el de "no estacionar", o en un escrito como los diarios, registros o boletines oficiales donde se publican las leyes aprobadas.

Repárese que la manifestación de la voluntad puede darse de manera clara o confusa, de forma precisa o imprecisa, unívoca, análoga o equívoca. Hay legisladores más técnicos que otros, algunos redactan las leyes de una manera más legible que otros. En cualquier caso, es imposible para el ser humano lograr una claridad, precisión y univocidad absoluta en las normas, menos aún cuando ellas son "preceptos generales" destinados a aplicarse en un sinnúmero de circunstancias no siempre previsibles por el legislador. ¿Por qué los derechos humanos han tenido tantos adeptos pese a la diferencia de pareceres en varios puntos neurálgicos? Creemos que es por el lenguaje vago que en esos puntos utilizan los pactos: todos hablan de derechos, aunque no todos entienden por ellos lo mismo... Hay una especie de esperanza de que estos pactos sean fruto del consenso, aunque ello no sea tan cierto.

Pero el problema no solo está en la forma de expresarse, sino también en el medio de comunicación. El lenguaje humano adolece de un margen de imprecisión ${ }^{25}$ y evoluciona a través de los siglos. Son poquísimas las palabras que en el diccionario muestran una sola definición, y menos son las palabras que pueden usarse en un solo sentido. Siempre se le pueden sacar sentidos análogos o metafóricos a cualquier término. Piénsese en el número $\pi$, cuyo significado es absolutamente unívoco; sin embargo, podríamos decirle a una persona con cierta ironía "eres como el número $\pi$ ”, por ser irracional igual que el número y porque nunca se la llegará a comprender. Un tribunal muy activista no dudará en sacarle nuevos sentidos a las palabras de la ley para hacerle decir lo que él desea que diga.

Con lo cual, hemos de concluir que el reconocimiento legal de los derechos siempre deja abierto un margen de posibilidades a la interpretación. Pensamos que ese margen es más amplio en los pactos de derechos humanos y en los catálogos de derechos insertos en las constituciones, porque estos se redactan de forma más genérica que las leyes inferiores.

\section{LOS LÍMITES DE LA POTENCIALIDAD: LO INDISPONIBLE}

En cualquier caso, no todo es pura posibilidad, no cualquier cosa puede ser derecho. Según vimos, la realidad extramental es la que ofrece la mayor cantidad de posibilidades jurídicas; la inteligencia humana sólo conoce unas pocas posibilidades y la voluntad (expresada social, cultural o históricamente) se decanta por unas específicas posibilidades jurídicas que la inteligencia ha captado. Más allá del espacio de las posibilidades justas está lo injusto, el espacio antijurídico $^{26}$. Resumimos todo esto en el gráfico de la pirámide invertida:

\footnotetext{
${ }^{25}$ La única posibilidad real de expresar absolutamente todo lo que se piensa, con suma precisión, claridad y de manera unívoca solo la ha tenido Dios al concebir intelectualmente al Hijo. Tanto no se le puede pedir al legislador.

${ }^{26}$ Como hemos explicado en otro lugar, lo que no es justo (o jurídico): o no tiene que ver con el derecho, o es contrario al derecho. Al conjunto de posibilidades justas actuales y potenciales lo llamamos "espacio jurídico"; al conjunto de posibilidades injustas "espacio antijurídico"; y al conjunto de cosas no relacionados con el derecho lo denominamos "espacio a-jurídico". Cfr. RIOFRÍO, 2016, p. 104-108.
} 


\section{[gráfico 1]}

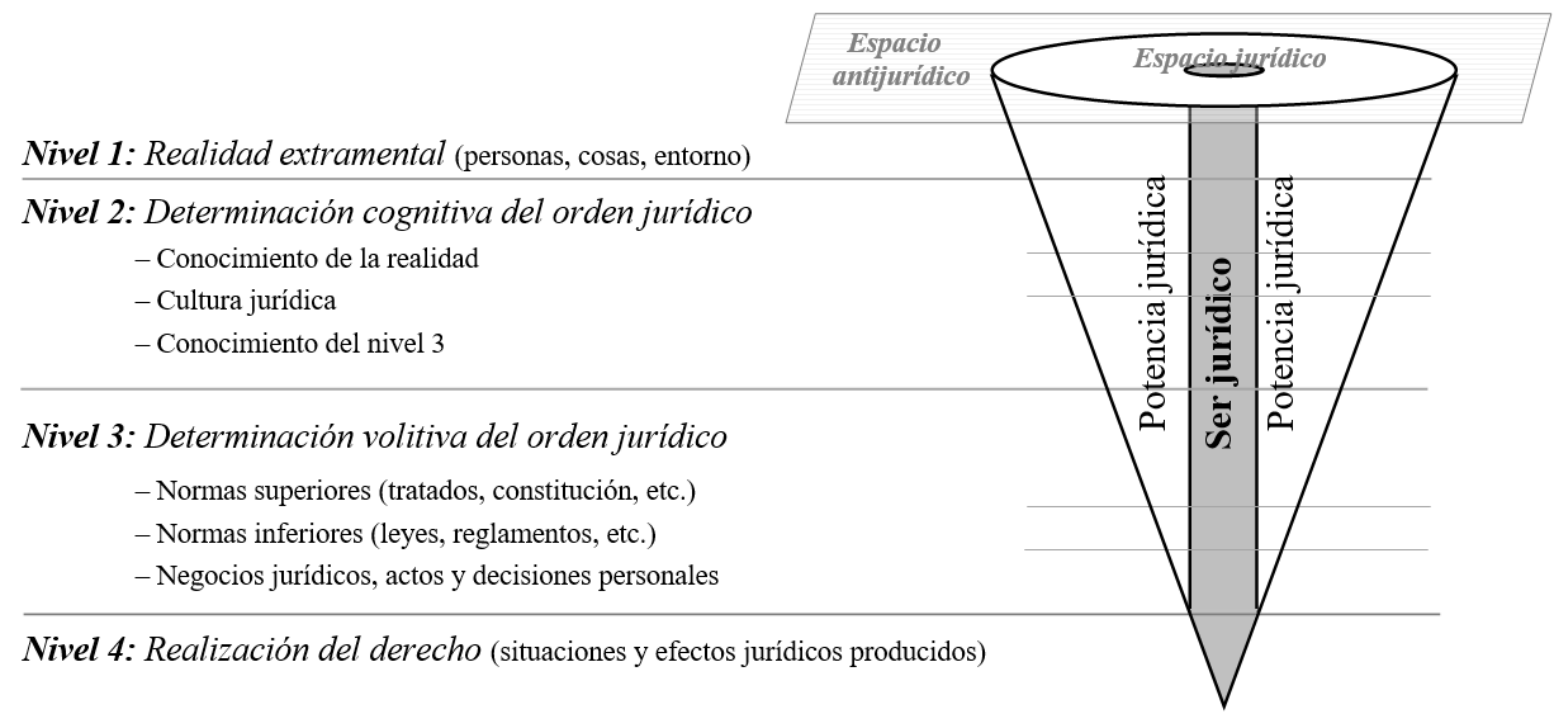

Destacamos que, metafísicamente, la potencia sigue al $\operatorname{ser}^{27}$. Lo que no es en absoluto, no puede llegar a ser nada. Lo que tiene una entidad débil, tendrá unas posibilidades limitadas. Ni un niño, ni una piedra saben matemáticas, ni tienen novia, pero el niño puede aprenderlas y al madurar contraer una relación, y la piedra nunca lo hará porque carece de las potencias de la inteligencia y la voluntad. Por otro lado, el ser determina las potencias, y las potencias determinan el fin: un teléfono sirve para llamar, no para coser, porque sus características le permiten comunicar a personas que están distantes; en cambio, una cosedora no sirve para llamar, pero su forma de ser y sus potencialidades permiten que sea un instrumento de costura. Y todo lo que coadyuva a realizar los fines de la naturaleza humana ha de ser tenido como valioso para el ser humano, porque valor es lo que se estima como bueno. De esta relación ontológica entre ser, potencia, fines y valores obtenemos los primeros eslabones de la fórmula SER HUMANOPOTENCIAS-FINES-VALORES-PRINCIPIOS-REGLAS-RELACIONES JURÍDICAS que hemos desarrollado en extenso en otro lugar ${ }^{28}$ y que es la columna vertebral de la pirámide invertida ${ }^{29}$. Sólo cuando la realidad humana se concrete en una relación jurídica, solo entonces habrá nacido un derecho subjetivo realizado, actual y concreto.

Si se entendió lo anterior, pienso que se entenderán mejor los límites del orden jurídico $\mathrm{y}$, al mismo tiempo, el concepto de indisponibilidad de los derechos fundamentales como un concepto flexible y progresivo. Indisponible es aquello "que no está disponible"30 para la

\footnotetext{
${ }^{27}$ Una famosa máxima dice operari sequitur esse. La idea se encuentra de algún modo en el Pseudodionisio (en De Ecclesiastica Hierarchia, c. 2: PG 3, 411), pero sobre todo la desarrolla Tomás de Aquino: operari sequitur esse, et modus operandi sequitur modum essendi (In III Sent., dist. 27, q. 1, a. 1, sol). El acto segundo (acción) se funda en el acto primero (ser). Lo que obra, primero tiene que haber sido (sentido dado por el Pseudodionisio) y, a la vez, quien obra, obra según lo que es (sentido que le da el Aquinate): la vista ve, no oye, porque el órgano está dispuesto para recibir la luz; el oído escucha, no huele, porque su constitución le permite captar sonidos, no olores. Pero para que la vista pueda ver y el oído escuchar, primero necesitan existir.

Aquí damos un giro más a la tuerca al observar que lo que obra, debe estar en potencia de obrar: nadie hace algo si primero no está en capacidad de hacerlo. Por eso, descomponiendo la idea, tenemos que: el obrar sigue a la potencia, y la potencia sigue al ser.

${ }^{28}$ Cfr. RIOFRÍO, 2016, Capítulo V, apartado 1.4.

29 Nótese que en cada escalón el espacio jurídico (el conjunto de posibilidades jurídicas) se va reduciendo progresivamente, y esto es justamente el corazón del concepto de pirámide invertida, que no es sino la reducción escalonada del espacio jurídico.

${ }^{30}$ RAE, 2017, única definición de "indisponible".
}

Revista de Direito Brasileira | São Paulo, SP | v. 18 | n. 7 | p. 49 - 62 |Set./Dez. 2017 
persona $^{31}$, aquello sobre lo cual el individuo no puede decidir, ni usar a voluntad, por cualquier razón: no se pueden usar máquinas teletransportadoras a otros planetas porque no existen, trenes porque no se han instalado en la ciudad, comida porque se acabó el dinero, armas porque una norma ética señala que no hay que matar, etc. ¿Qué cosas no están disponibles en el derecho? Creemos que las siguientes:

(i) En primer lugar, los límites de la realidad extramental, con su ser, su modo de ser y su modo de obrar, con sus potencias y sus fines, con su valor objetivo. Nadie puede decidir que las montañas del Ecuador son de oro (ser y modo de ser), ni que el oído puede ver (potencias), ni que el agua líquida sirve para martillar (fin), ni que los objetos deban caer en la tierra a más de $7,8 \mathrm{~m} / \mathrm{s}^{2}$ (modo de obrar), ni que un gramo de diamantes vale más que un kilo de diamantes de la misma calidad (valor). La realidad impone sus límites al derecho.

Con frecuencia los iusnaturalistas aluden a esta indisponibilidad de la realidad humana (o de la naturaleza humana) para justificar la inviolabilidad, inalienabilidad, imprescriptibilidad, etc. de los derechos humanos. Si bien esta representa el analogatum prínceps, hemos de matizar que no es el único tipo de indisponibilidad posible.

(ii) En segundo lugar, los límites del conocimiento humano de la realidad. Cuando se conocía poco del petróleo, sobre él sólo se podían hacer contratos de extracción, distribución y venta para encender antorchas; hoy nuestro conocimiento es más profundo y esto ha hecho nacer la rama del derecho de los hidrocarburos que pone a nuestra disposición una gran cantidad de actos y negocios jurídicos relacionados con el petróleo. El desconocimiento impone imperceptiblemente sus límites al derecho, pero puede ser superado con el aprendizaje.

Un gran sector de iusnaturalistas destaca la necesidad de utilizar la razón práctica para obtener los primeros principios y reglas del derecho, que por ello son indisponibles. Quienes se dedican a la argumentación jurídica también resaltan la importancia de que el derecho sea razonable. En uno y otro caso habría que añadir que el razonamiento jurídico, para que sea válido, debe partir de la realidad. No se juzga en nuestros tribunales a Lord Voldemort, ni a Dark Vader, por más malvados que sean, ni nuestras sentencias son libros de novela ficción; se juzgan hechos reales cometidos por personas concretas, que poseen de hecho un ser, una naturaleza, unas potencias, unos fines y un valor determinado. El conocimiento de todo ello y la corrección del razonamiento sin duda limita el derecho, a su modo.

Recordamos ahora las consideraciones tomistas sobre la forma en que la norma inferior se deriva de la superior (que para el Aquinate es la ley natural):

"Hay que advertir que una norma puede derivarse de la ley natural de dos maneras: bien como una conclusión [conclusio] de sus principios, bien como una determinación [determinatio] de algo indeterminado o común. El primer procedimiento es semejante al de las conclusiones demostrativas que en las ciencias se infieren de los principios; el segundo se asemeja a lo que pasa en las artes, donde las formas comunes reciben una determinación al ser aplicadas a realizaciones especiales, y así vemos que el constructor tiene que determinar unos planos comunes reduciéndolos a la figura de esta o aquella casa. Pues bien, hay normas que se derivan de los principios comunes de la ley natural por vía de conclusión; y así, el precepto "no matarás" puede derivarse a manera de conclusión de aquel otro que manda "no hacer mal a nadie". Y hay otras normas que se derivan por vía de determinación; y así, la ley natural establece que el que peca sea castigado, pero que se le castigue con tal o cual pena es ya una determinación añadida a la ley natural" (Suma Teológica: I-II, q. 95, a. 2 sol.).

En esta línea, podríamos decir que se pueden distinguir dos tipos de conocimiento humano de la realidad: uno conclusivo y otro determinativo. Las conclusiones racionales son

${ }^{31}$ Solo la persona puede propiamente disponer de algo, porque sólo ella tiene inteligencia y voluntad. Revista de Direito Brasileira | São Paulo, SP | v. 18 | n. 7 | p. 49 - 62 | Set./Dez. 2017 
indisponibles para la voluntad: si la razón concluye que hay derecho a algo, o que no lo hay, el hombre no puede contradecirla. En cambio, si el razonamiento no es conclusivo, sino que simplemente determina unos principios o directivas generales (como la regla del castigo que permite hacerlo de variadas formas), entonces la voluntad puede escoger algún modo - entre los posibles - de cumplir con ese principio o directiva. Así pues, aquello que se deduce de los razonamientos conclusivos es absolutamente indisponible, mientras que lo que se deduce de los razonamientos determinativos es relativamente indisponible (basta que no contravenga el principio o directiva).

Hervada va más allá, y señala que el derecho natural puede fijar ("conclusivamente" diríamos, tomando el lenguaje del Aquinate) varias cosas: el derecho, el título, su medida o una regla. No se tiene derecho a la vida porque a un grupo de geniales hombres se les ocurrió redactar una declaración, sino porque la vida representa un insigne valor y la inteligencia humana comprende que debe respetarse. De ahí se deriva la norma jurídica de no matar, salvo en caso de legítima defensa. También la naturaleza fija ciertas medidas, como la de indemnizar los daños causados, no más, no menos; aunque a veces deja la medida indeterminada, como cuando señala que ha de castigarse de manera proporcional a la gravedad del delito ${ }^{32}$.

(iii) Los límites de la cultura jurídica. Ella le indica a cada sociedad cómo celebrar los contratos, cómo realizar los actos jurídicos, qué se espera del ciudadano, algunas cosas que están prohibidas... Los matrimonios pueden celebrarse de mil formas, pero en la mentalidad popular sólo hay una. Cada cultura hace primar ciertos valores: la veracidad en la cultura anglosajona, la amistad en las culturas caribeñas, la puntualidad y corrección en la cultura alemana o suiza, la flexibilidad en la cultura italiana, etc. Se tratan, por tanto, de valores subjetivos, pero fundados sobre la realidad objetiva: la veracidad, la amistad, la puntualidad, la corrección y la flexibilidad son todos valores objetivos porque objetivamente permiten al ser humano alcanzar sus fines. Quizá en alguna circunstancia convenga saltarse una regla de tránsito para llegar más rápido al hospital, o engañar en un juego de póker, o retrasarse para atender a un enfermo, etc.; en estos casos no se cuestiona que la regla, la veracidad o la puntualidad sean buenas en sí mismas, sino que estos valores ceden en función de otro valor mayor (como salvar la vida, la diversión que no daña, la atención del enfermo). La cultura actúa ad modum naturae, y para quien no conoce otra forma cultural, impone imperceptiblemente sus límites al derecho; si se conocieran otras formas culturales como "posibles" ("posibles para mí"), entonces la cultura sí sería disponible.

De esta manera concordamos con los constructivistas que hablan de una cierta objetividad e indisponibilidad de las normas, valores y principios adoptados por una sociedad. Simplemente matizamos que esa "indisponibilidad" es una "indisponibilidad débil" "33, menos fuerte que la indisponibilidad de la realidad extramental.

(iv) Los límites del conocimiento del derecho positivo. Quien no conoce en absoluto el derecho positivo, no está obligado a seguirlo. Piénsese en las comunidades amazónicas no contactadas, desconectadas del régimen estatal. ¿Quién irá a cobrarles un impuesto? Primero habría que informarles que existe un estado, que ahí se cobran impuestos, con qué fin se hace esto, etc. Distinto es el caso del citadino que debe poner los esfuerzos necesarios para conocer las leyes de su país, y la pena por no poner sus buenos oficios es justamente la de no aceptar que incumpla las leyes por desconocerlas. Aun así, si tal desconocimiento fuere justificado (por ejemplo, por no haberse publicado la ley), la persona podrá alegarlo. Por eso, el desconocimiento del derecho positivo limita parcialmente el derecho.

(v) Los límites del derecho positivo, según su jerarquía. La norma constitucional transforma muchas materias disponibles en indisponibles para la gente (no para el Constituyente). Si la Asamblea Constituyente opta por la democracia, la monarquía dejará de ser una opción; si opta por las elecciones directas, los compromisarios no estarán disponibles. Lo mismo sucede

${ }^{32}$ Cfr. HERVADA. 1981.

${ }^{33}$ En el mismo sentido MASSINI CORREAS, 2004.

Revista de Direito Brasileira | São Paulo, SP | v. 18 | n. 7 | p. 49 - 62 |Set./Dez. 2017 
con las leyes que especifican el mandato constitucional: lo que ellas impongan no estará a disposición del Presidente, de los alcaldes o de los ciudadanos (aunque sí estará a disposición del Legislativo y del Constituyente). Igual con los reglamentos del Presidente, frente a los demás poderes y frente a los gobernados.

Por lo dicho, estamos de acuerdo con los positivistas que afirman que los derechos humanos son indisponibles porque se suscribió un tratado que así lo dice. Sin embargo, matizamos que esa "indisponibilidad" no es tan fuerte como la "indisponibilidad" de la realidad extramental (que también pesa sobre estos derechos).

(vi) Las situaciones y efectos jurídicos producidos tampoco son disponibles en sí mismos. Situaciones jurídicas son, por ejemplo, el derecho a la vida, el derecho al helado recién comprado, la obligación de pagar el préstamo, la patria potestad sobre el hijo. Los mencionados derechos, obligaciones y potestades son indisponibles en cierto sentido. Más claro es el tema cuando hablamos de obligaciones: yo no puedo decidir si debo pagar o no el préstamo... ¡yo debo pagarlo, sin más! Pero lo mismo sucede con los derechos y potestades, y con cualquier situación y efecto jurídico producido: lo tengo o no lo tengo. Ciertamente puedo disponer del helado de compré para regalárselo a un familiar, pero puedo hacerlo porque efectivamente tengo derecho al helado. Tener o no un derecho es algo que se deduce racionalmente (la razón ve si hay justificativos), no es un capricho de la voluntad. Si la tenencia de un derecho, obligación o potestad fuera en sí misma disponible, todos optaríamos por ser ricos, libres de toda obligación y, en definitiva, omnipotentes.

\section{CONCLUSIONES}

Hasta aquí hemos llegado a las siguientes conclusiones:

1. La proliferación de derechos se ha realizado bajo diferentes justificaciones: (i) ser derechos de naturaleza; (ii) haberse positivizado en un texto escrito por autoridad; (iii) existir una necesidad, aspiración o emoción humana; y, finalmente, (iv) contribuir al bien del ecosistema o de los animales.

2. Como la naturaleza y dignidad humana son inderogables, los "derechos de la naturaleza humana" consagrados al inicio del movimiento constitucional tuvieron las características de ser indisponibles, imprescriptibles, inalienables, inembargables, inviolables, etc. Quizá por costumbre, el resto de derechos proclamados años más tarde — no siempre bajo una cosmovisión iusnaturalista - heredaron las mismas características.

3. En propiedad, para que exista un derecho subjetivo debe darse: (i) un título justificativo del derecho; (ii) una cosa sobre la que recae el derecho; y, (iii) una posibilidad de disponer de esa cosa.

4. En realidad los derechos subjetivos solo los ostentan quienes han trabado alguna relación jurídica. Sólo ahí fulano puede exigir algo a mengano. Los derechos redactados en las declaraciones de derechos humanos, en las constituciones o en la doctrina, solo son "derechos hipotéticos" (que nacerán cuando en la realidad se configure la hipótesis).

5. Los derechos fundamentales presentan una alta potencialidad, en varios sentidos: (i) primero, quien tiene un derecho, está facultado a hacer varias cosas; (ii) la realidad permite a quien la domina hacer muchísimas cosas, más de las que conoce u opta por hacer; (iii) mientras la persona conozca más la realidad, más cosas podrá hacer con ella; (iv) entre todas las opciones que la inteligencia capta que cabe hacer con la realidad, la voluntad sólo escoge una, concretando las posibilidades. Esta concreción voluntaria de las posibilidades jurídicas se hace a través de las normas superiores e inferiores, de los actos y negocios jurídicos. El texto escrito de las normas, actos y negocios jurídicos no es unívoco, y puede tener varios sentidos, lo que significa una apertura de posibilidades jurídicas para el lector. 
6. En todo caso, la potencialidad de los derechos hipotéticos no es ilimitada. Hay cosas que son indisponibles, imprescriptibles, inalienables, inembargables, inviolables, etc. En concreto, limitan la potencialidad: (i) la realidad; (ii) el conocimiento de la realidad y el razonamiento sobre ella; (iii) la cultura jurídica; (iv) el conocimiento del derecho positivo; (v) el mismo derecho positivo; y, (vi) las situaciones y efectos jurídicos producidos.

7. Por tanto, la indisponibilidad es un concepto flexible y progresivo. El analogatum prínceps de la indisponibilidad jurídica es el de la "indisponibilidad de la realidad". Luego vienen, en su orden: el del conocimiento de la realidad, la cultura, el conocimiento del derecho positivo, el mismo derecho positivo, y finalmente las situaciones y efectos jurídicos.

\section{REFERENCIAS}

\section{Doctrina y revistas}

BALBÍN, R. María de. La relación jurídica natural. Pamplona: Eunsa, 1985.

BEUCHOT, Mauricio. La fundamentación filosófica de los derechos humanos en Jacques Maritain. Tópicos, 4, 1993, p. 9-26.

DE OCKHAM, Guillermo. Opus nonaginta dierum. En HERVADA, Javier, Lecciones de Filosofía del derecho. Pamplona: Eunsa, 2000.

GALLEGO GARCÍA, Elio. Tradición jurídica y derecho subjetivo. Dykinson: Madrid, 2005.

GUILLÉN, Tomás. En el “Estudio preliminar” a la obra de Leibniz. Madrid: Tecnos,1991.

HERVADA, Javier. Introducción crítica al Derecho natural. Pamplona: EUNSA, 1981.

LEIBNIZ, Gottfried W. Los elementos del Derecho natural. Madrid: Tecnos, 1991.

MASSINI CORREAS, Carlos Ignacio. Constructivismo ético y justicia procedimental en John Rawls. México: UNAM, 2004.

McINERNY, Ralph. Natural Law and Human Rights. The American Journal of Jurisprudence, 36, 1991, p. 1-14.

MIRAS, Jorge, CANOSA, Javier y BAURA, Eduardo. Compendio de derecho administrativo canónico. Navarra: Eunsa, 2001.

PSEUDO-DIONISIO. De Ecclesiastica Hierarchia. PG 3.

RADBRUCH, Gustav. Gesetzliches Unrecht und übergesetzliches Recht. Müller: Heidelberg, 1946.

REAL ACADEMIA ESPAÑOLA. Diccionario de la Lengua Española. Madrid, 2017.

RIOFRÍO MARTÍNEZ-VILLALBA, Juan Carlos. La teoría de la pirámide invertida y los clásicos del derecho constitucional. Actas del ler. Congreso Iberoamericano y XXVIII Jornadas Argentinas de Filosofía Jurídica y Social, dictada en Buenos Aires, el 16 de octubre de 2014. 
RIOFRÍO MARTÍNEZ-VILLALBA, Juan Carlos. Las causas metafísicas como fuentes del derecho. Revista Telemática de Filosofía del Derecho, 15, 2012, p. 259-308.

RIOFRÍO MARTÍNEZ-VILLALBA, Juan Carlos. Metafísica jurídica realista. Buenos Aires: Marcial Pons, 2016.

RORTY, Richard. Human Rights, Rationality and Sentimentality. En S. SHUTE y S. HURLEY (eds.), On Human Rights. Oxford: The Oxford Amnesty Lectures, 1994.

SAGÜES, Néstor. Teoría de la Constitución. Buenos Aires: Astrea, 2004.

SUÁREZ, Francisco. De legibus: lib. I.

TALAMANCA, Mario. Istituzioni di diritto romano. Milán: Giuffrè Editore, 1990.

TOMÁS DE AQUINO. Scriptum super libros Sententiarum. (Comentario a las sentencias de Pedro Lombardo), 1252-1256.

TOMÁS DE AQUINO. Suma Teológica, París-Italia, 1265-1272. Traducción al castellano de AA. VV. (BAC), Suma Teológica de Santo Tomás de Aquino, 4a ed. Madrid: BAC, 2001.

VILLEGAS, Abelardo. La universidad y los derechos humanos. La universidad en la encrucijada. Unión de Universidades de América Latina, México, 1992.

VILLEY, Michel. Critique des droits de l'homme. Anales de la Cátedra Francisco Suarez, 12/2 1972, p. 12.

\section{Normativa}

Declaración de los Derechos del hombre y del ciudadano de 1789

Declaración de Virginia de 1776

Acta de Independencia de los Estados Unidos de América

Constitución de Turquía, 1961.

Constitución de 1 República de Ecuador, 2008.

Constitución del Neuquén (Argentina). 